\title{
The Effects of Climate Extremes on Health: A Literature Review
}

\author{
Nguyen D. Khoi, Le T. Trang, Hoang T. T. Huong, Nguyen T. Huong, Nguyen K. Hang, Le Kien
}

\begin{abstract}
We assess contemporary research on the societal implications of catastrophic weather events during the previous century, and we link it to changes in associated meteorological phenomena. The fundamental conclusion drawn from the literature is that most studies find that climate extremes cause significant losses in health, as measured by excess mortality. Most estimates of the costs of weather and climatic extremes show rising losses over the last several decades. The majority of related weather and climate extremes, on the other hand, show no comparable increases over time. This shows that rising losses are mostly the result of increased susceptibility as a result of a range of developments, such as an increase in population in high-risk coastal areas.
\end{abstract}

\section{Introduction}

Trong những năm gần đây, các hiện tượng thời tiết cực đoan đã dẫn đến thiệt hại kinh tế lớn hơn bao giờ hết. Các khoản lỗ hàng tỷ đô la hiện nay xảy ra với tần suất ngày càng tăng. Xu hướng thua lỗ khiến nhiều người kết luận rằng thế giới đã chứng kiến những thay đổi về tần suất và / hoặc cường độ của các sự kiện cực đoan. Những nhận thức này không chỉ là những suy đoán vu vơ chúng làm nền tảng cho các quyết định chính sách với những phân nhánh quan trọng về xã hội, kinh tế và chính trị, chẳng hạn như những vấn đề liên quan đến biến đổi khí hậu và thiên tai. Bài báo này tìm cách cung cấp một đánh giá về các nghiên cứu gần đây về các xu hướng tổn thất liên 
quan đến các sự kiện cực đoan. Những hiện tượng này là lũ lụt, bão, bão mùa đông, cực nóng và lạnh, các sự kiện liên quan đến giông bão (mưa đá, lốc xoáy, sét) và hạn hán.

Bài báo này trình bày một cuộc khảo sát các tài liệu thực nghiệm nghiên cứu mối quan hệ giữa kết quả sức khỏe, khí hậu và sự thích ứng với các khí hậu khắc nghiệt. Mục tiêu của bài báo là làm nổi bật nhiều lỗ hổng còn tồn tại trong tài liệu thực nghiệm. Kết luận chính xuất hiện từ các tài liệu là mặc dù có nhiều bộ dữ liệu và bối cảnh đa dạng, hầu hết các nghiên cứu đều phát hiện ra rằng khí hậu khắc nghiệt dẫn đến giảm đáng kể sức khỏe, thường được đo bằng tỷ lệ tử vong vượt mức. Về vai trò của thích ứng trong việc giảm thiểu tác động của khí hậu khắc nghiệt đối với sức khỏe, kiến thức sẵn có còn hạn chế, một phần do có ít bộ dữ liệu thực tế về các hành vi thích ứng. Cuối cùng, bài báo thảo luận về tác động của các bằng chứng hiện có đối với việc đánh giá các tác động tiềm tàng đến sức khỏe con người của biến đổi khí hậu toàn cầu.

\section{Method}

Cơ sở dữ liệu Web of Science được tìm kiếm từ ngày 1 tháng 1 năm 1950, cho đến ngày tìm kiếm. Mục đích của bài đánh giá của chúng tôi là tổng hợp thông tin đã xuất bản trước đây về ảnh hưởng của các hiện tượng khí hậu. Khi các cụm từ tìm kiếm, các biến thể khác nhau của "thiên tai" đã được sử dụng. Các nghiên cứu bổ sung được phát hiện bằng cách tìm kiếm bằng tay. Để tiến hành sàng lọc và đánh giá toàn văn cho tất cả các bài báo, các tác giả đã sử dụng Covidence, một công cụ tổ chức điện tử để đánh giá có hệ thống. Dân số nghiên cứu, vị trí và mức độ phơi nhiễm của dân số nghiên cứu đều được tính đến.

Nguy cơ sai lệch được đánh giá ở các mức kết quả nghiên cứu cho mỗi nghiên cứu duy nhất dựa trên nguồn dữ liệu, dân số nghiên cứu, quy trình lấy mẫu, phương pháp thu thập và phân tích dữ 
liệu, và bất kỳ đặc điểm cụ thể nào của dân số. Các nghiên cứu có phương pháp luận bị nghi ngờ hoặc bị lỗi đã bị loại trừ. Từ các nghiên cứu đáp ứng các tiêu chí bao gồm, dữ liệu về khoảng thời gian, quốc gia nghiên cứu và tiểu vùng, xung đột được xác định, thiết kế nghiên cứu, dân số tham khảo, loại phơi nhiễm, kết quả sức khỏe, khả năng tiếp cận các nhu cầu cơ bản, tỷ lệ tử vong và mối liên quan giữa phơi nhiễm và kết quả đã được trích xuất vào một biểu mẫu trích xuất dữ liệu. Nếu có sã̃n, dữ liệu về các yếu tố bảo vệ và giảm thiểu đối với kết quả sức khỏe trẻ em đã được tóm tắt. Khi phát hiện thiếu dữ liệu, các tác giả đã được liên hệ trong thời gian sớm nhất.

\section{Results and Discussion}

Barnett (2007) điều tra số lượng tử vong do tim mạch hàng ngày từ 107 thành phố trong Nghiên cứu ô nhiễm không khí về bệnh tật và tử vong quốc gia Hoa Kỳ. Các ước tính được tính trung bình theo thời gian và theo mùa bằng cách sử dụng phân tích tổng hợp. Vào mùa hè năm 1987, tỷ lệ tử vong do tim mạch tăng trung bình do nhiệt độ tăng $10^{\circ} \mathrm{F}$ là $4,7 \%$. Vào mùa hè năm 2000 , rủi ro với nhiệt độ cao hơn đã biến mất (-0,4\%). Ngược lại, sự gia tăng nhiệt độ vào mùa thu, mùa đông và mùa xuân có liên quan đến việc giảm số người chết và sự giảm này không đổi theo thời gian. Tử vong do tim mạch liên quan đến nhiệt ở người cao tuổi đã giảm theo thời gian, có thể là do sử dụng điều hòa nhiệt độ nhiều hơn, trong khi nguy cơ gia tăng với nhiệt độ liên quan đến lạnh vẫn còn.

Le và Nguyen (2021a) khai thác sự biến đổi ngoại sinh của lượng mưa mà trẻ em tiếp xúc trong chín tháng trong bụng mẹ, họ thấy rằng sự thay đổi lượng mưa ảnh hưởng xấu đến tình trạng nhân trắc học của trẻ em dưới 5 tuổi ở 55 quốc gia có thu nhập thấp và trung bình. Hơn nữa, hậu quả của việc thai nhi tiếp xúc với sự thay đổi lượng mưa rất rõ ràng trong năm đầu đời của đứa trẻ và kéo dài ở một mức độ nào đó ở các độ tuổi sau này. Các phân tích không đồng nhất của họ cho 
thấy thêm rằng trẻ em có hoàn cảnh khó khăn, chẳng hạn như các hộ gia đình nghèo và thất học, đặc biệt dễ bị ảnh hưởng bởi sự thay đổi lượng mưa trong thời kỳ mang thai.

Kalkstein \& Greene (1997) chỉ ra rằng các thành phố ở phía Nam và Tây Nam cho thấy mối quan hệ về thời tiết / tỷ lệ tử vong thấp hơn vào mùa hè. Trong mùa đông, sự gia tăng tỷ lệ tử vong do khối lượng không khí gây ra ít hơn đáng kể so với mùa hè. Mặc dù tỷ lệ tử vong hàng ngày vào mùa đông thường cao hơn mùa hè, nhưng nguyên nhân tử vong gây ra hầu hết tỷ lệ tử vong trong mùa đông không thay đổi nhiều theo nhiệt độ. Sử dụng các mô hình ước tính biến đổi khí hậu cho những năm 2020 và 2050 , người ta ước tính rằng tỷ lệ tử vong vào mùa hè sẽ tăng đáng kể và tỷ lệ tử vong vào mùa đông sẽ giảm nhẹ, ngay cả khi mọi người đã thích nghi với sự ấm áp tăng lên. Do đó, ước tính tỷ lệ tử vong liên quan đến thời tiết tăng ròng khá lớn nếu khí hậu ấm lên như các mô hình dự đoán.

Chestnut et al. (1998) báo cáo kết quả phân tích hồi quy được sử dụng để xác định các đặc điểm thời tiết và kinh tế xã hội của 44 khu vực đô thị có thể giải thích sự khác biệt về tỷ lệ tử vong do thời tiết nắng nóng. Kết quả cho thấy sự thay đổi của nhiệt độ tối thiểu hàng ngày vào mùa hè có thể là một trong những yếu tố quan trọng nhất. Phát hiện này cho thấy rằng sự thích nghi về mặt sinh học hoặc hành vi xảy ra ở những khu vực luôn nóng, nhưng không phải ở những nơi mà sự thay đổi nhiệt độ tối thiểu hàng ngày lớn hơn. Kết quả cũng cho thấy rằng sự khác biệt về mức độ sẵn có của máy điều hòa không khí, tiêu chuẩn sống và chất lượng nhà ở góp phần vào sự khác biệt về tỷ lệ tử vong do thời tiết nắng nóng, nhưng những yếu tố này giải thích tỷ lệ biến động về tỷ lệ tử vong do thời tiết nắng nóng nhỏ hơn nhiều so với sự thay đổi nhiệt độ hàng ngày tối thiểu. Kết quả cho thấy liệu biến đổi khí hậu có dẫn đến tỷ lệ tử vong do thời tiết nắng nóng cao hơn hay không có thể phụ thuộc vào tác động lên sự thay đổi của nhiệt độ tối thiểu hàng ngày cũng như sự thay đổi nhiệt độ tuyệt đối.. 
Piver và cộng sự. (1999) cho thấy rằng đột quỵ nhiệt có liên quan đến việc tiếp xúc lâu dài với nhiệt độ không khí cao, thường xảy ra vào các tháng mùa hè của tháng 7 và tháng 8 ở Tokyo, Nhật Bản. Cũng trong tháng 7 và tháng 8 , người dân Tokyo thường xuyên phải tiếp xúc đồng thời với nồng độ cao của các chất ô nhiễm không khí. Để đánh giá tác động của những lần phơi nhiễm tổng hợp này, số ca vận chuyển cấp cứu đột quỵ hàng ngày / triệu cư dân Tokyo được phân theo giới tính và ba nhóm: 0-14, 15-64; và> 65 tuổi, trong các tháng 7 và 8 năm 1980-1995. Một mô hình hồi quy được xây dựng bằng cách sử dụng nhiệt độ tối đa hàng ngày (Tmax) và nồng độ trung bình hàng ngày của $\mathrm{NO} 2$ và $\mathrm{O} 3$ làm hiệp biến mô hình. Các chỉ số phân loại đã được thêm vào để có thể so sánh số trường hợp đột quỵ do nhiệt dự kiến theo độ tuổi và giới tính. Thời gian trễ từ 14 ngày trong Tmax và các hiệp biến chất lượng không khí và các điều khoản để tính đến sự tương tác giữa các cặp hiệp biến mô hình cũng được bao gồm như các yếu tố nguy cơ bổ sung. Mô hình tuyến tính tổng quát (GLM), giả định cấu trúc lỗi Poisson cho các trường hợp vận chuyển khẩn cấp đột quỵ nhiệt, được sử dụng để xác định hiệp biến nào là yếu tố nguy cơ đáng kể đối với đột quỵ nhiệt cho ba nhóm tuổi nam và nữ. Tmax và nồng độ $\mathrm{NO} 2$ trong cùng ngày là những yếu tố nguy cơ đáng kể nhất đối với đột quỵ nhiệt ở tất cả các nhóm tuổi nam và nữ. Số ca vận chuyển cấp cứu đột quỵ do nắng nóng / triệu dân ở nam nhiều hơn nữ trong cùng nhóm tuổi. Số ca vận chuyển cấp cứu đột quỵ thấp nhất / triệu cư dân xảy ra đối với nữ 0-14 tuổi và số ca vận chuyển cấp cứu đột quỵ cao nhất / triệu cư dân xảy ra đối với nam> 65 tuổi.

Le and Nguyen (2021b) điều tra mức độ ảnh hưởng của việc tiếp xúc với sốc nhiệt độ trong tử cung ảnh hưởng đến kết quả cân nặng khi sinh ở Việt Nam. Khai thác sự khác biệt giữa các quận và thời điểm thụ thai trong các quận, huyện, họ cho thấy rằng sự gia tăng một độ lệch chuẩn về nhiệt độ so với mức bình thường của địa phương (khoảng $0,52^{\circ} \mathrm{C}$ ) trong ba tháng đầu của thai kỳ sẽ làm giảm $67 \mathrm{~g}$ hoặc $2,2 \%$ trọng lượng khi sinh của trẻ. . Phân tích tính không đồng nhất của họ 
cho thấy rằng trẻ sơ sinh sống ở các vùng nông thôn, được sinh ra từ các bà mẹ nghèo và có trình độ học vấn thấp đặc biệt dễ bị sốc nhiệt độ..

Ye và cộng sự. (2001) đã nghiên cứu mức độ phơi nhiễm với nhiệt độ tối đa hàng ngày cao hơn và nồng độ các chất ô nhiễm không khí ở Tokyo trong các tháng mùa hè của tháng 7 và tháng 8 từ năm 1980 đến năm 1995 và ảnh hưởng của chúng đối với việc vận chuyển cấp cứu tại bệnh viện đối với các bệnh tim mạch và hô hấp đối với nam và nữ> 65 tuổi . Các bệnh tim mạch là đau thắt ngực, suy tim, tăng huyết áp và nhồi máu cơ tim. Các bệnh về đường hô hấp là hen suyễn, viêm phế quản cấp và mãn tính, và viêm phổi. Ngoại trừ viêm phổi, nhiệt độ tối đa hàng ngày không liên quan đến việc vận chuyển cấp cứu tại bệnh viện. Tuy nhiên, việc tăng nhiệt độ tối đa hàng ngày có liên quan đến việc giảm vận chuyển cấp cứu trong bệnh viện do tăng huyết áp. Tuy nhiên, nồng độ nitơ điôxít hoặc hạt <hoặc $=10$ microm có liên quan đến việc vận chuyển cấp cứu hàng ngày tại bệnh viện vì đau thắt ngực, suy tim, nhồi máu cơ tim, hen suyễn, viêm phế quản cấp và mãn tính và viêm phổi. Đối với suy tim, tăng huyết áp, nhồi máu cơ tim, hen suyễn, viêm phế quản mãn tính và viêm phổi, số ca vận chuyển cấp cứu dự kiến hàng ngày đối với nam nhiều hơn nữ. Đối với chứng đau thắt ngực và viêm phế quản cấp tính, không có sự khác biệt về số lần vận chuyển khẩn cấp hàng ngày dự kiến trên một triệu giữa nam và nữ. 